DEMOGRAPHIC RESEARCH

VOLUME 30, ARTICLE 39, PAGES 1129-1156

PUBLISHED 9 APRIL 2014

http://www.demographic-research.org/Volumes/Vol30/39/

DOI: 10.4054/DemRes.2014.30.39

Research Article

Household ecology and out-migration among ethnic Karen along the Thai-Myanmar border

Daniel M. Parker

James W. Wood

Shinsuke Tomita
Sharon DeWitte

Julia Jennings

Liwang Cui

(c) 2014 Parker, Wood, Tomita, DeWitte, Jennings \& Cui.

This open-access work is published under the terms of the Creative Commons Attribution NonCommercial License 2.0 Germany, which permits use, reproduction \& distribution in any medium for non-commercial purposes, provided the original author(s) and source are given credit.

See http:// creativecommons.org/licenses/by-nc/2.0/de/ 


\section{Table of Contents}

$\begin{array}{lll}1 & \text { Introduction } & 1130\end{array}$

$2 \quad$ Objective 1133

$\begin{array}{lll}2.1 & \text { Study population } & 1334\end{array}$

3 Methods 1136

3.1 Data 1136

$\begin{array}{lll}3.2 & \text { Statistical analysis } & 1137\end{array}$

$\begin{array}{lll}3.3 & \mathrm{C} / \mathrm{P} \text { weights and sensitivity analysis } & 1138\end{array}$

$4 \quad$ Results 1140

4.1 Summary statistics $\quad 1140$

4.2 Survival models 1141

$\begin{array}{lll}4.3 & \text { Sensitivity analysis } & 1142\end{array}$

5 Conclusions 1444

$6 \quad$ Acknowledgements 1149

$\begin{array}{ll}\text { References } & 1150\end{array}$ 


\title{
Household ecology and out-migration among ethnic Karen along the Thai-Myanmar border
}

\author{
Daniel M. Parker ${ }^{1}$ \\ James W. Wood ${ }^{2}$ \\ Shinsuke Tomita ${ }^{3}$ \\ Sharon DeWitte ${ }^{4}$ \\ Julia Jennings ${ }^{5}$ \\ Liwang $\mathrm{Cui}^{6}$
}

\begin{abstract}
BACKGROUND

Local migration in developing-world settings, particularly among rural populations, is an important yet understudied demographic process. Research on migration in such populations can help us test and inform anthropological and demographic theory. Furthermore, it can lead to a better understanding of modern population distributions and epidemiologic landscapes.
\end{abstract}

\section{OBJECTIVE}

The purpose of this study was to investigate the potential relationships between household- and individual-level factors on out-migration among Karen villagers along the Thai-Myanmar border.

\section{METHODS}

We used a random effects hazard model to investigate the relationship of household consumer-producer $(\mathrm{C} / \mathrm{P})$ ratios, the number of household members, and an individual's sex on the odds of outmigration. We then used simulations in order to test the sensitivity of our model to our $\mathrm{C} / \mathrm{P}$ ratio weighting scheme.

${ }^{1}$ Departments of Anthropology and Demography, Pennsylvania State University, U.S.A. E-Mail: Daniel@shoklo-unit.com.

${ }^{2}$ Departments of Anthropology and Demography, Pennsylvania State University, U.S.A.

${ }^{3}$ Center for Southeast Asian Studies, Kyoto University, Japan.

${ }^{4}$ Department of Anthropology, University of South Carolina, U.S.A.

${ }^{5}$ Department of Anthropology, University at Albany, SUNY, U.S.A.

${ }^{6}$ Department of Entomology, Pennsylvania State University, U.S.A. 


\section{RESULTS}

We found that the number of household members is predictive of increased outmigration. Household C/P ratios were positively associated with out-migration in children but negatively associated with out-migration in working age adults. Finally, adult males were much more likely to move out of the household than were adult females.

\section{CONCLUSIONS}

While household-level factors are important with regard to out-migration, the relationships between such household-level factors and out-migration are complex and vary by the individual's age and sex. Our study offers two novel concepts to household demography and migration studies. First, this study offers a new approach to evaluating weighting schemes for $\mathrm{C} / \mathrm{P}$ ratios. Second, we show that household level factors are important at units of time (two-week intervals) that are not normally studied by demographers.

\section{Introduction}

Studies of migration in small-scale, indigenous agricultural populations are important not only for demographic research, but also for understanding the mechanisms behind the distribution of populations across landscapes and the spread of infectious diseases (Ferrari et al. 2008; Fix 1999; Stoddard et al. 2009). For example, because migration, like many demographic behaviors, is not uniform by age (in many populations, agespecific migration rates tend to be highest among young adults and their dependent children), migration can have significant impacts on the age structure of both the source and receiving populations (Rogers \& Castro 1981). For certain infectious diseases, such as malaria, migration across international borders is a key factor of pathogen reintroduction and constitutes a major challenge for the elimination of infectious diseases (Tatem and Smith 2010). However, migration in small agricultural populations remains an understudied demographic process, especially in developing countries and remote regions (Curran 2002; Entwisle, Malanson, Rindfuss, and Walsh 2008; Massey and Espana 1987). Detailed migration data in rural developing areas can be difficult to come by, for several reasons. First, some migration is illegal, making documentation difficult. Second, migration opportunities may arise suddenly, meaning that people with no prior intention to migrate may quickly change their minds. Third, a lack of resources and physical infrastructure (roads, etc.) makes it difficult to carry out migration surveys. Fourth, many migrants in Sub-Saharan Africa, Southeast Asia, and Latin America are 
also ethnic minorities who live on the margins of society, meaning that taxpayer money is unlikely to be directed toward their concerns.

A variety of cultural, social, epidemiological, political, and economic factors can influence migration decisions (Curran and Saguy 2001; De Jong and Gardner 1981; Fields 1976; Muth 1971; Portes and Sensenbrenner 1993; Sassen 1988; Stark and Bloom 1985; Todaro 1980). Socio-cultural norms dictate marriage patterns with respect to both age and post-marital residence rules. The epidemiological landscape of a region might influence settlement and migration patterns, and could potentially lead to outmigration from a region that is especially burdened with disease. In modern times national governments are likely to have legal restrictions on where a person can travel and settle. Foreign nationals, for example, may need special documentation for moving legally across international borders, and even with documentation may be restricted in their ability to settle in foreign nations. And, of course, the importance of economics cannot be overemphasized in migration decisions. Migrants in poor rural areas may be drawn to relatively wealthy urban areas (Fields 1976; Muth 1971; Stark 1991; Todaro 1980). Even within relatively homogeneous rich or poor regions there can be spatial heterogeneity in resources, potentially leading to micro-level movement.

Demographic researchers have attempted to use migration models to describe the migration process, and those models can be classified broadly by their unit of analysis. For example, several early models were macro in scale, focusing on the economics of entire nations or even multi-national regions (Fields 1976; Muth 1971). In the latter case, poor nations may act as sources of migrants whereas wealthy nations may act as sinks for them. Over time, the focus on macro-scale models was largely replaced by a focus on micro individual-scale models (Lee 1966; Sjaastad 1962; Stark and Bloom 1985; Todaro 1980). This change of focus largely followed the realization that migrants are not homogenous. That is, not every person in a poor region migrates; in fact some people who live in wealthy regions migrate as well. A variety of factors has been considered in micro-level models, including the lure of increased capital and the escape from poor economic conditions, as well as the draw of migration flows that are already in place (e.g., cumulative causation) (Bohra-Mishra and Massey 2011; Massey 1990; Massey and Espana 1987). Finally, some more recent models have realized that there is an important middle ground in the level of focus with regard to migration models. Individuals live in households, communities, villages, cities, and regions; these higher levels of organization, and the interactions between them, should not be ignored (De Jong and Gardner 1981; Portes and Sensenbrenner 1993). All these factors are likely to be important in influencing migration decisions.

With regard to anthropological demography, perhaps the most fundamental demographic unit to consider is the household. Households are clearly composed of distinct individuals, but individuals do not have their own demography, and economic 
strategies are arguably made mostly at the household level, ${ }^{7}$ perhaps especially within small-scale indigenous farming communities in developing-world settings (Netting 1982, 1993; Wood 2014). In such populations individual well-being, which in the most basic sense means the ability to feed oneself, can be attributed largely to household farming success or failure. In the absence of alternative subsistence strategies, individuals who live in farming households that are experiencing shortages in food or other resources suffer the consequences of those shortages. Conversely, individuals who live in households with an abundance of resources are likely to benefit from that abundance.

Household surpluses and shortages are not only a function of agricultural production; they are also related to the demographic structure of the household. One measure of the demographic structure of a household is the consumer-producer $(\mathrm{C} / \mathrm{P})$ ratio. A.V. Chayanov $(1925,1966)$ was probably the first person to calculate C/P ratios and include them in a model of household economics. Chayanov was largely interested in Russian peasants and was essentially looking at dynamics in peasant productivity over the long term (several decades) and in terms of large-scale population and economic dynamics. However, Chayanov's C/P ratios are also a measure of individual household well-being in a Malthusian sense, as they can also indicate inadequacies of productive capacity within the household resulting from changes in household age and sex structure over time.

A few studies have actually looked at $\mathrm{C} / \mathrm{P}$ ratios with regard to household dynamics and household well-being over time (Hammel 2005; Jennings et al. 2011; Lee and Campbell 2007; Lee and Kramer 2002; Sparks, Wood, and Johnson 2013). For example, households that have recently been established by a newlywed couple will have low $\mathrm{C} / \mathrm{P}$ ratios. In many rural and agricultural societies offspring will be born into a household within a few years of its establishment, resulting in a fairly rapid increase in the $\mathrm{C} / \mathrm{P}$ ratio. As those offspring grow into adolescence they begin to contribute more to the household economy, and the $\mathrm{C} / \mathrm{P}$ ratio decreases once again. Finally, assuming that all offspring eventually move out as the original household founders age, the original founders will enter into senescence and once again the $\mathrm{C} / \mathrm{P}$ ratio will increase as they become less capable of contributing to their own household economy than they were as young adults (Hammel 2005; Lee and Kramer 2002).

Household characteristics can therefore have profound implications for household members. For example, the age and sex structure of a household may be important with regard to migration decisions. For individuals who live in resource-poor households migration may offer a new source of economic subsistence. Conversely, individuals from poor households may not have the resources necessary (travel costs, etc.) for

\footnotetext{
${ }^{7}$ Remittances to households are also an important factor, meaning that even family members outside of the household can contribute to household economies.
} 
migrations. Ultimately, a household's membership size, relative wealth, and the age and sex of its inhabitants may be important with regard to household-member nutrition, longevity, marriage practices, and potentially migration (Garnier et al. 2003; Gage et al. 1996; Hadley et al. 2011; Madhavan et al. 2009). At the same time, migration itself will influence the household's subsequent $\mathrm{C} / \mathrm{P}$ ratio, and this fact may play a part in the decision to migrate.

\section{Objective}

Previous research in the developing world has shown that household characteristics such as dependency or $\mathrm{C} / \mathrm{P}$ ratios, household size, and relative household wealth are strong predictors of demographic and health outcomes. For example, some research has indicated that households may regulate their size and age structure, especially with regard to working-age adults, through the migration of their members (Madhavan et al. 2009; Hadley et al. 2011; Katz 2000). Not all household members contribute equally to the household economy and not all consume equally from the household bounty. As an extreme example, migrants who are away from home yet sending back remittances may consume none of the household's food store while still contributing to that store. Households with relatively limited and constrained resources, and with more consumers than producers, may also be more likely to have household members either suffer poor nutrition or move out of the household (Benefice, Cames, and Simondon 1999; Garnier et al. 2003). Furthermore, households with excess producers may also be more capable of coping with the loss of extra producers. How household economic crises (e.g., the loss of household producers) are handled is likely to be construed, in part, through cultural and societal norms.

Of course, not all migration or population movement is the result of household crises. Historically, some populations have been mobile for subsistence reasons. For example, many hunter-gatherers engage in seasonal mobility strategies to exploit game and other resources while avoiding resource depletion in any one area (Lieberman 1993). Similarly, some pastoralists migrate with their livestock in pursuit of fresh pastures. Also, many young adults leave home in order to establish their own households or to join other households through marriage, regardless of subsistence strategy. In regions where schooling is available but not local, school-age children may move out of the household at the beginning of the school year or term. The demographic profile of the household members who move out in each of these cases is likely to vary according to the reason the person has left and by cultural norms (Behrman and Wolfe 1984; Curran and Saguy 2001; Jacobsen and Levin 1997; Rogers and Castro 1981). In this paper we explore the potential influences of household and 
individual characteristics in household out-migration in four ethnic Karen villages along the Thai-Myanmar border in Tak Province, Thailand. We use mixed-effects survival models to examine the influence of various covariates on the hazard of leaving a household (out-migration).

\subsection{Study population}

The Karen are one of the largest ethnic minority groups in both Myanmar and Thailand and they inhabit both sides of the Thai-Myanmar border. An accurate census in Myanmar has not been conducted since the 1930s, and current estimates of the total Karen population vary between three and seven million (Barron et al. 2007; United Nations High Commissioner for Refugees 2007). Over the last half century the Karen have been engaged in periodic warfare with the ruling government in Myanmar (Burma), and at times there have been mass evacuations of Karen from the Myanmar side of the border to the relative safety of Thailand. Many Karen therefore live in refugee camps on the Thai side of the border, whereas others continue to live in rural agricultural villages or in cities in both Myanmar and Thailand. As of January 2013 over 100,000 Karen were living in refugee camps on the Thai side of the border (The Border Consortium 2013). According to the 2010 Thai Census, approximately 440,000 people reported usually speaking Karen in their homes (Office of National Statistics, Thailand 2010).

The Karen are subsistence farmers who have, over the last several decades, also become more engaged in Thailand's market economy. While the bulk of agricultural efforts for most Karen in this area remain irrigated-rice production for household subsistence and local consumption, some now grow produce for export and others hire themselves out as agricultural laborers. Several researchers have done work on Karen socio-cultural patterns, health, and demography (Kunstadter 1972, 1983; Lee et al. 2006; Nakano 1980; Omori and Greksa 2002; Rajah 2008; Skeldon 1985; Walker 2001). Most of the detailed demographic work concerning the Karen was conducted by Kunstadter and colleagues during the mid- to late- $20^{\text {th }}$ century. Kunstadter's work was broadly focused on population dynamics and agroforestry (Kunstadter 1972; 1983). Little work has been done on migration among the Karen, but Kunstadter suggested that Karen migration was limited in its geographic range (1972). Males commonly moved out of their villages for marital purposes, typically moving to or near their female spouse's family household. Labor exchanges between households related by kinship were also common and would occur seasonally according to the agricultural calendar (Figure 1). Household formation is also heavily influenced by cultural norms. The 'ideal' household, according to research done by Kunstadter and fieldwork conducted 
by the author, consists of a married couple and their children, as well as the spouse of their youngest married daughter and the children from that marriage. Older daughters and their families may also live nearby (Kunstadter 1984).

Figure 1: Net out-migration, agricultural and school calendar. Image adapted from Nakano (1980), migration data come from the present study and the agricultural and school schedules come from field work done by D.M.P.

January

December

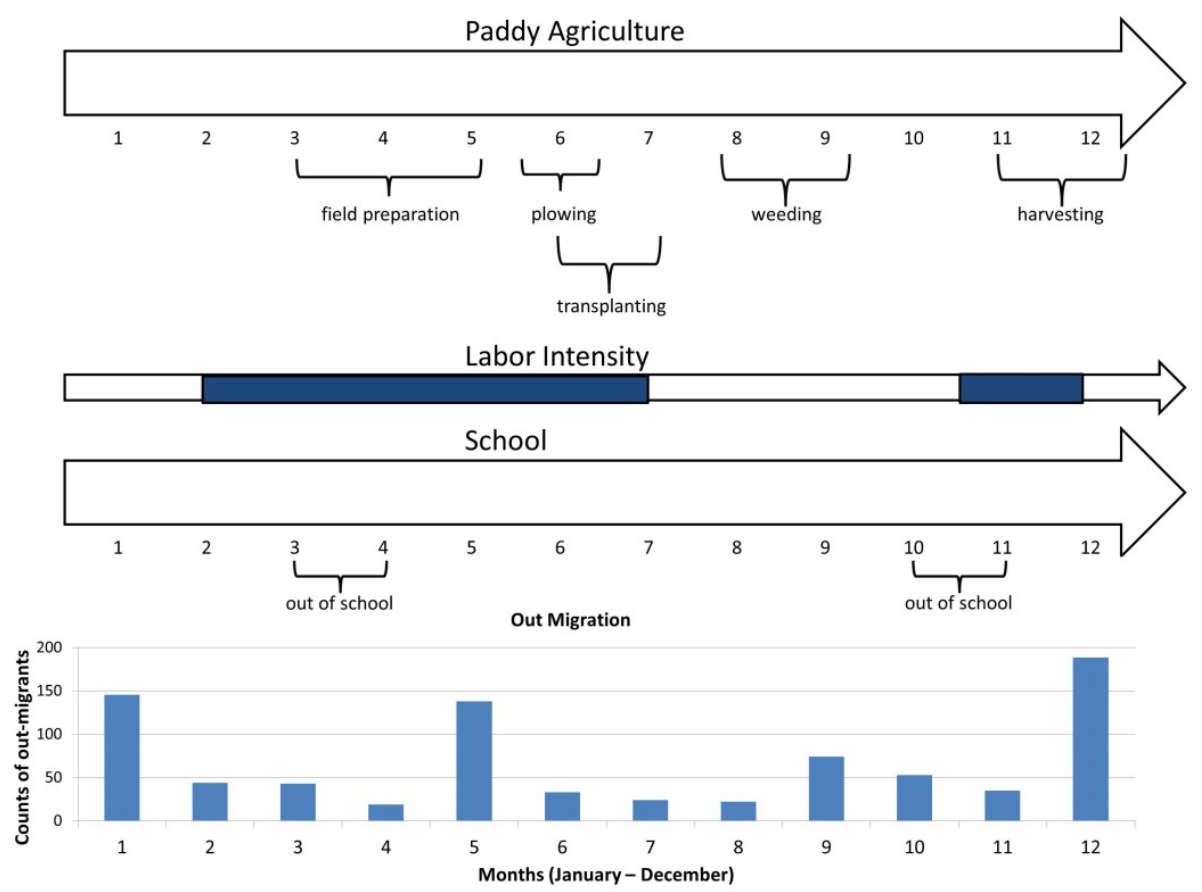

Most of these generalities hold true today, though the political and economic realities under which the Karen currently live obviously influence migration and movement patterns. The international border is extremely porous and movement across it is frequent. Karen villagers from the Myanmar side visit weekly markets on the Thai side and many of the Karen who live on the Thai side frequently visit relatives and friends on the Myanmar side. Also, the abundant resources in Myanmar, including 
lumber, precious gems, and cattle, lead many people (some of whom are Karen) to move across the border surreptitiously. Some even maintain farming plots on the Myanmar side of the border. Such extra-legal movement can be difficult to document and quantify. Finally, while the Karen are primarily subsistence farmers, they are not isolated from the larger Thai and Myanmar economies. Rather than being tied solely to the household and its agricultural plots, household members are aware of, and take advantage of, outside economic opportunities. Many will exploit these outside opportunities in order to diversify the household economy, providing a buffer against instability in household food stores and income. Those migrants who remain tied to their agricultural households are likely to migrate during off-peak times of the year, when agricultural work is less strenuous and their labor is not immediately needed (Figure 1).

\section{Methods}

\subsection{Data}

Our data come from a U.S. National Institutes of Health-funded project that is aimed at controlling malaria in the Greater Mekong Subregion of Southeast Asia (Cui, Yan, Sattabongkot, Chen, et al. 2012; Cui, Yan, Sattabongkot, Cao et al. 2012). Four study villages along the Thai-Myanmar border were selected, ranging in size from 500 to 2000 inhabitants. All the study villages were on the Thai side, as access to the adjacent part of Myanmar is restricted. The villages were selected because of their history of malaria caseloads (this area has some of the highest incidences of malaria in Thailand) as well as their willingness to participate in the research. Full demographic surveys were carried out in the villages twice, listing the number of individuals in each household by name, sex, and self-reported age and assigning a unique identification code to each individual and to each household. Follow-up surveillance, which began in October 2011, is conducted every two weeks and will continue for several years. The data used in this paper cover the period October 2011 through November 2012. During the surveys healthcare fieldworkers moved through each of the villages, going from house to house recording health status and changes in household size and composition (which were coded as resulting from birth, death, in-migration, or out-migration). When a household member who had been given an identification code during the initial census was not present in a household, the field workers asked other adult household members about their status. Remaining household members were specifically asked how long the absent household member was going to remain away from the household. Household members who were not expected back within four weeks were coded as out- 
migrants. Our migration data are therefore interval-censored, in that we know a migration occurred during a two-week window, but we do not know exactly when in that two-week window the migration occurred. Covariates included individual, survey week, sex and age, the number of individuals within a household, and the household $\mathrm{C} / \mathrm{P}$ ratio (estimated as discussed below). Since a household's size and $\mathrm{C} / \mathrm{P}$ ratio are affected by the subtraction of a household member resulting from out-migration, we included a two-week lag for those two household predictors to avoid simultaneity effects.

We acknowledge that our measure of migration (based on leaving for an expected one-month period of time) is relatively arbitrary and that there are several other household-level factors that are not included in our data that are likely to be important with regard to migration decisions. The goal of the project (so as to distinguish it from this specific research) was to analyze temporal age and sex patterns in malaria infections within and across the study villages rather than to analyze demographic outcomes.

\subsection{Statistical analysis}

We used piecewise mixed-effects logistic regression to model the hazards of individual out-migration with respect to household-level predictors. The logistic model, including a random intercept, is:

$$
\log \left[\frac{p_{i t}}{1-p_{i t}}\right]=\alpha_{h i}+\beta_{1} x_{i t 1}+\ldots+\beta_{k} x_{i t k}
$$

where $p_{i t}$ is the conditional probability that the $i$-th individual will move out of his or her household (hi) during a particular two-week observation window $t, \alpha_{h i}$ is a randomeffect intercept allowing for unobserved heterogeneity among households, and the $\beta \mathrm{s}$ are the estimated regression coefficients for the covariates $(x)$. The random intercept $\alpha_{h i}$ is assumed to have a normal distribution with mean $\mu_{\alpha}$ and variance $\sigma_{\alpha}^{2}$, 'hyperparameters' to be estimated directly from the data. We used the transformation $100\left(\mathrm{e}^{\beta}-1\right)$ to estimate the percent change in the odds of an out-migration event for every unit increase in that particular covariate.

Since migration intensity may vary over the study period, possibly increasing after agricultural work is done, we tested two different specifications for time, linear and quadratic, using Akaike information criterion (AIC) and Bayesian information criterion (BIC) to assess the two specifications. The linear effect of time proved to be a better fit. Furthermore, migration patterns, motivations, and drivers can vary strongly by age (Rogers and Castro 1981). We therefore stratified our model by age group, running 
separate models for those aged 0-12, 13-69, and 70 plus (Table 1), in order to account for age in our models ${ }^{8}$. Finally, we standardized household C/P ratios (mean $=0$ and standard deviation $=1$ ) to facilitate interpretation of model estimates. The lagged household covariates were used to examine potential correlations between the household size and C/P ratio from the previous survey (two weeks prior) and their effects on the probability that a household member had moved out by the time of the current survey.

Table 1: Weighting scheme for $\mathrm{C}$ (consumption) and $\mathrm{P}$ (production) by age and sex group

\begin{tabular}{lllll}
\hline & \multicolumn{2}{c}{ consumption } & \multicolumn{2}{c}{ production } \\
\cline { 2 - 5 } age group & male & female & male & female \\
\hline $\mathbf{0}$ to $\mathbf{4}$ & 0.2 & 0.2 & 0 & 0 \\
$\mathbf{5}$ to $\mathbf{1 2}$ & 0.5 & 0.5 & 0.3 & 0.3 \\
$\mathbf{1 3}$ to $\mathbf{6 9}$ & 1 & 1 & 1.1 & 1.1 \\
$\mathbf{7 0}$ plus & 0.9 & 0.9 & 0.7 & 0.7 \\
\hline
\end{tabular}

\section{3 $\mathrm{C} / \mathrm{P}$ weights and sensitivity analysis}

Some previous studies have used dependency ratios (usually defined as the ratio of household members ages $<15$ and $>65$ to those ages 15-65) as an indicator of household demographic pressure on economic and demographic behavior (Hadley et al. 2011; Reyna 1976). However, dependency ratios assume that children and elderly household members do not contribute to the household economy but only take from it. There is a wealth of literature indicating that this is not the case (Cain 1977; Caldwell 1976; Lee and Kramer 2002), though the contributions of children are usually smaller than those of their parents (Stecklov 1999; Kaplan 1994). Thus, to calculate the C/P ratio of each household, each household member is assigned a weight for $\mathrm{C}$ and for $\mathrm{P}$ (separately) according to their age and sex. The resultant $\mathrm{C} / \mathrm{P}$ ratio of a household is arguably a better measure of household economy than is the dependency ratio.

\footnotetext{
${ }^{8}$ Since migration occurs for a variety of reasons, it is an oversimplification to treat migration events as identical. A competing risks model might therefore be a better model for understanding different types of migration. However, our data do not allow us to classify different migration types. We know that an individual has left the household, but we do not know why. We hope to rectify this deficiency in future research.
} 
Furthermore, a high $\mathrm{C} / \mathrm{P}$ ratio can indicate Malthusian stress within the household, where there is more consumption need than there is production capacity.

A particularly vexing and intractable problem with regard to this weighting scheme, however, is the question of how we actually estimate $\mathrm{C}$ and $\mathrm{P}$ for one particular study population. At least one intensive ethnographic study has attempted to create precise calculations for the C/P ratio (Kramer and Boone 2002; Kramer 2005; Lee and Kramer 2002), but even this excellent effort is in many ways deficient and therefore unconvincing. Given the importance of $\mathrm{C} / \mathrm{P}$ ratios and the unknown nature of the actual weights, we created a set of rather arbitrary but plausible weights for each of eight age and sex groups (Table 1) for both consumption and production, i.e., a total of 16 weights. Our initial weights were roughly based on Karen Kramer's intensive ethnographic work with the Maya (Kramer and Boone 2002; Lee and Kramer 2002) as well as Nakano's fieldwork with the Karen (Nakano 1980). We then implemented a 'bootstrap-like' simulation method to test the sensitivity of our model results to errors in our assumed $\mathrm{C} / \mathrm{P}$ ratio weighting scheme. Each simulation drew pseudorandom numbers for weights based on a uniform distribution; we based ranges for the uniform distributions on Lee and Kramer's (2002) empirical data from the Maya (Table 2). Pseudorandom numbers were drawn for each age and sex group and separately for C and $\mathrm{P}$, weights were then applied to those age and sex groups, and the survival models were estimated using the randomly-drawn weighting scheme. At the end of a model run the process began again, with a new set of pseudorandom weights assigned to each age and sex group. Each simulation was run for 500 iterations for each age stratum of the survival model. The results from our simulations consisted of a distribution of coefficient estimates for the effect of household C/P ratio on the log odds of outmigration.

Table 2: $\quad$ Range of weights for simulations. A uniform distribution was used to draw pseudorandom numbers from the weight ranges listed below. The ranges for weights are drawn from Kramer and Boone (2002)

\begin{tabular}{lcrcr}
\hline & \multicolumn{2}{c}{ consumption } & \multicolumn{2}{c}{ production } \\
\cline { 2 - 5 } age group & male & female & male & female \\
\hline $\mathbf{0}$ to $\mathbf{4}$ & $0-0.4$ & $0-0.4$ & 0 & 0 \\
$\mathbf{5}$ to $\mathbf{1 2}$ & $0.3-0.7$ & $0.3-0.7$ & $0.1-0.5$ & $0.1-0.5$ \\
$\mathbf{1 3}$ to $\mathbf{6 9}$ & $0.8-1.2$ & $0.8-1.2$ & $0.9-1.3$ & $0.9-1.3$ \\
$\mathbf{7 0}$ plus & $0.7-1.1$ & $0.7-1.1$ & $0.5-0.9$ & $0.5-0.9$ \\
\hline
\end{tabular}




\section{Results}

\subsection{Summary statistics}

Out of 181,073 distinct observations from the censuses and prospective demographic surveillance, our dataset included 1,604 out-migration events, 924 (58\%) of them male and 680 (42\%) female. Figure 2 illustrates the age and sex patterns of out-migration across the four study villages. At most ages males migrate more often than females. However, this pattern is most pronounced between the ages of 15 and 50. Female outmigration peaks around age 15 whereas male out-migration peaks around age 20 . After age 15 female out-migration quickly decreases, whereas high male migration is sustained between ages 15 and 25 .

Figure 2: Age-specific migration rates by sex

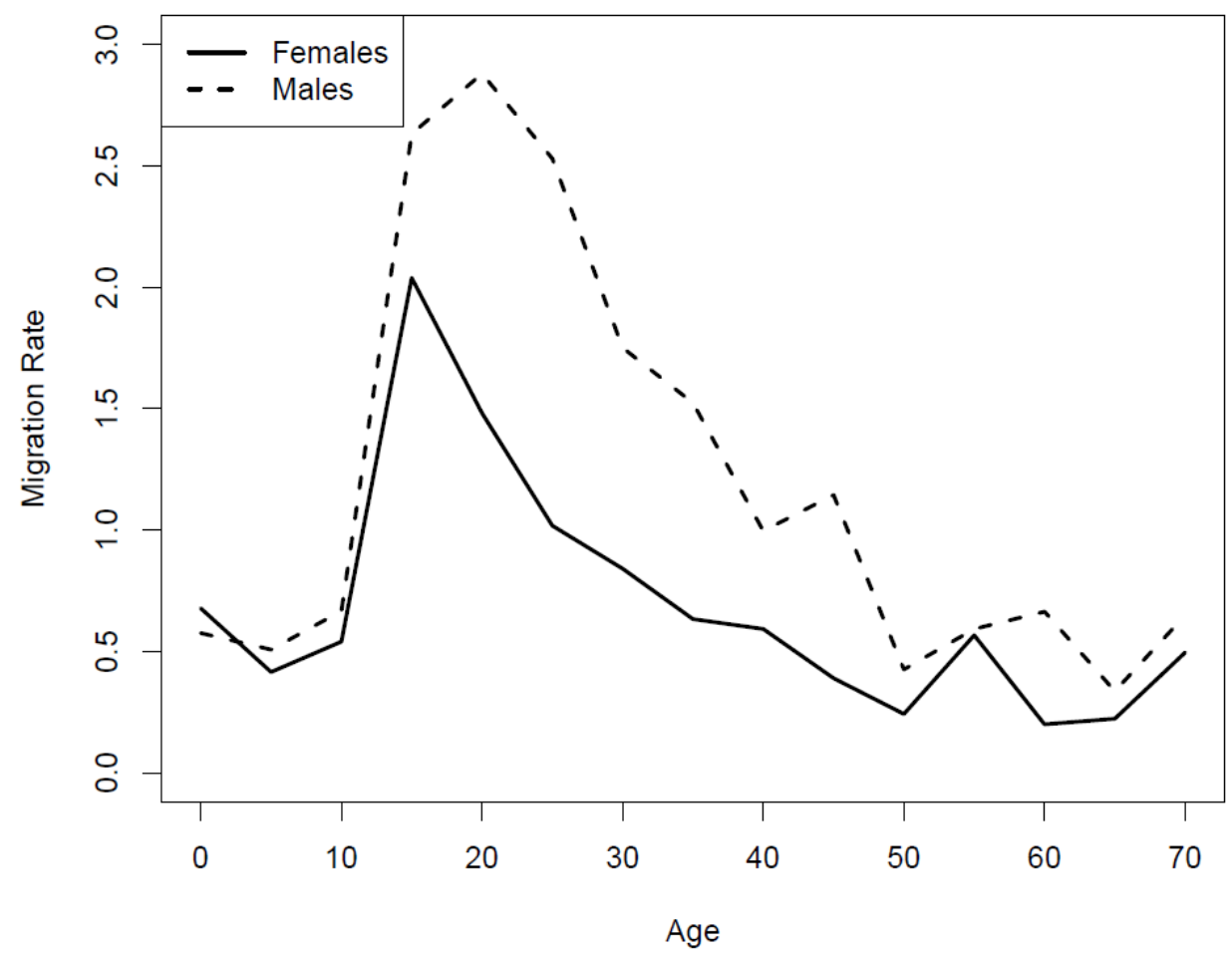




\subsection{Survival models}

The effect of time (survey week) in each of the models was negligible (Tables 3-5). Sex, household C/P ratio, and household size all showed relatively strong effects. For children under age 13 (Table 3 ) the effect of household $\mathrm{C} / \mathrm{P}$ ratio was both strong and positive $(\hat{\beta}=0.12$; $95 \% \mathrm{CI}$ : $0.08,0.16)$, that is, it increased the odds of an out-migration event. The effect of household size was also strong and positive. The addition of one household member resulted in a 30\% increase in the odds of a household member under age 13 moving out. Not surprisingly, sex appears to have no effect on out-migration in children.

Table 3: Model results for children under age 13

\begin{tabular}{lrccc}
\hline Covariate & Coefficient & Standard Error & t-value & p-value \\
\hline Survey Week & 0.0031 & 0.0058 & 0.5400 & 0.5868 \\
C/P Ratio & 0.1219 & 0.0408 & 2.9900 & 0.0028 \\
House Size & 0.2595 & 0.0486 & 5.3400 & $<.0001$ \\
Female & 0.0443 & 0.1371 & 0.3200 & 0.7469 \\
\hline
\end{tabular}

In stark contrast to the model for children, the model for working-age adults (ages 13 through 69 (Table 4)) indicated a strong negative relationship between household $\mathrm{C} / \mathrm{P}$ ratio and out-migration $(\hat{\beta}=-0.63$; 95\% CI: $-0.73,-0.53)$. The effect of household size remained strong and positive, indicating a $24 \%$ increase in the odds of an outmigration with the inclusion of one more household member. Also, an individual's sex was a relatively strong predictor of out-migration within this age group, with females being about $39 \%$ less likely to move out compared to males.

Table 4: $\quad$ Model results for those aged 13 to 69

\begin{tabular}{lcccc}
\hline Covariate & Coefficient & Standard Error & t-value & p-value \\
\hline Survey Week & -0.0018 & 0.0030 & -0.6100 & 0.5395 \\
C/P Ratio & -0.6275 & 0.1000 & -6.2800 & $<.0001$ \\
House Size & 0.2140 & 0.0258 & 8.3100 & $<.0001$ \\
Female & -0.4940 & 0.0652 & -7.5700 & $<.0001$ \\
\hline
\end{tabular}


Our model for elderly out-migrants (Table 5) suffered from a small number of cases, with only 19 out-migrations over the study period. Standard errors and coefficients were too similar to warrant direct interpretation of our model results with this age group.

Table 5: $\quad$ Model results for those over age 69

\begin{tabular}{lcccc}
\hline Covariate & Coefficient & Standard Error & t-value & p-value \\
\hline Survey Week & 0.0511 & 0.0477 & 1.0700 & 0.2838 \\
C/P Ratio & 0.1869 & 0.6352 & 0.2900 & 0.7686 \\
House Size & 0.1890 & 0.1631 & 1.1600 & 0.2467 \\
Female & -0.1680 & 1.2070 & -0.1400 & 0.8893 \\
\hline
\end{tabular}

In summary, in our models for children and adults, households with more members were more likely to experience individuals moving out. Also, the effect of $\mathrm{C} / \mathrm{P}$ ratio is strong in both child and adult out-migration, but the direction of the effect differed (positive for children, negative for working-age adults). Finally, working-age females were much less likely to migrate out than were working-age males.

\subsection{Sensitivity analysis}

Our sensitivity analyses indicate the robustness of our survival models with regard to the effect of C/P ratio on out-migration (Figures 3-5). Across the 500 simulated models for children under age 13 , the mean effect size for $\mathrm{C} / \mathrm{P}$ ratio was 0.15 ( $\mathrm{min}=0.02$ and $\max =0.33$ ) (Table 6, Figure 3). If we were to take 0.15 as the true coefficient size it would indicate a $16 \%$ increase in the odds of an out-migration with an increase of one standard deviation in a household C/P-ratio. We should note than such an increase in the $\mathrm{C} / \mathrm{P}$ ratio is an extremely large change. The mean coefficient size for working-age adults was $-0.61(\min =-1.24, \max =-0.01)$ (Figure 4). The mean coefficient size indicates a $46 \%$ decrease in the odds that an individual will move out with an increase of one standard deviation in household $\mathrm{C} / \mathrm{P}$ ratio. Finally, our simulation results with regard to elderly out-migrants further indicate the lack of predictive power for this model stratum (Figure 5). The distribution of estimated coefficients straddles zero, with an average coefficient of $-0.05(\min =-3.95, \max =1.94)$. 
Table 6: $\quad$ Summary statistics for simulation results

\begin{tabular}{lccccc}
\hline Model & mean & median & $\begin{array}{c}\text { standard } \\
\text { deviation }\end{array}$ & min & $\max$ \\
\hline $\mathbf{0}$ to $\mathbf{1 2}$ & 0.15 & 0.16 & 0.06 & 0.02 & 0.33 \\
$\mathbf{1 3}$ to 69 & -0.61 & -0.59 & 0.25 & -1.24 & 0.01 \\
$\mathbf{7 0}$ plus & -0.05 & 0.01 & 0.65 & -3.95 & 1.94 \\
\hline
\end{tabular}

Figure 3: Distribution of simulated coefficient estimates for the effect of $C / P$ ratio on out-migration in children under age 13

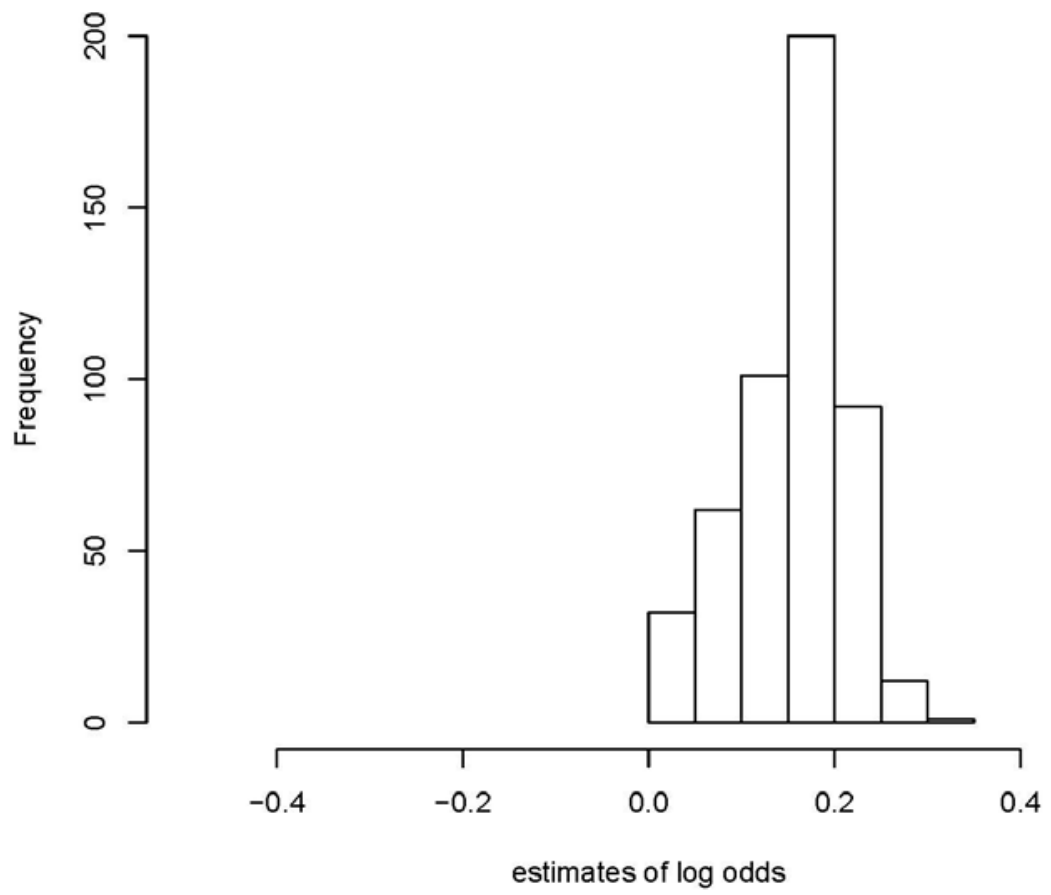




\section{Conclusions}

Several previous researchers have investigated potential influences of $\mathrm{C} / \mathrm{P}$ ratios on various demographic and economic outcomes. However, our model specifically investigates the relationships between household dynamics and C/P ratios, over time, with regard to out-migration. To our knowledge, this is the first time that this substantive topic has been investigated.

Figure 4: Distribution of simulated coefficient estimates for the effect of C/P ratio on out-migration in individuals between the age 13 and 69

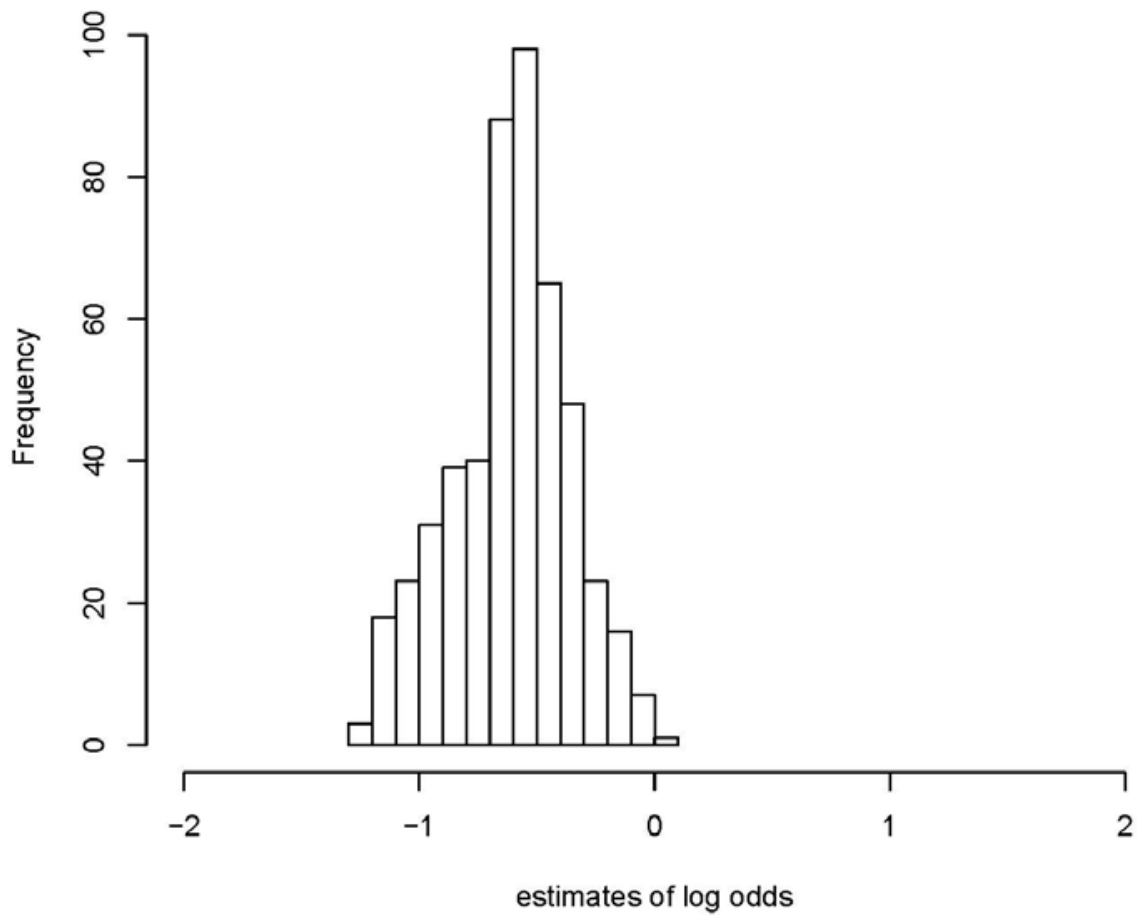


Figure 5: Distribution of simulated coefficient estimates for the effect of $\mathbf{C} / \mathrm{P}$ ratio on out-migration in adults over age 69

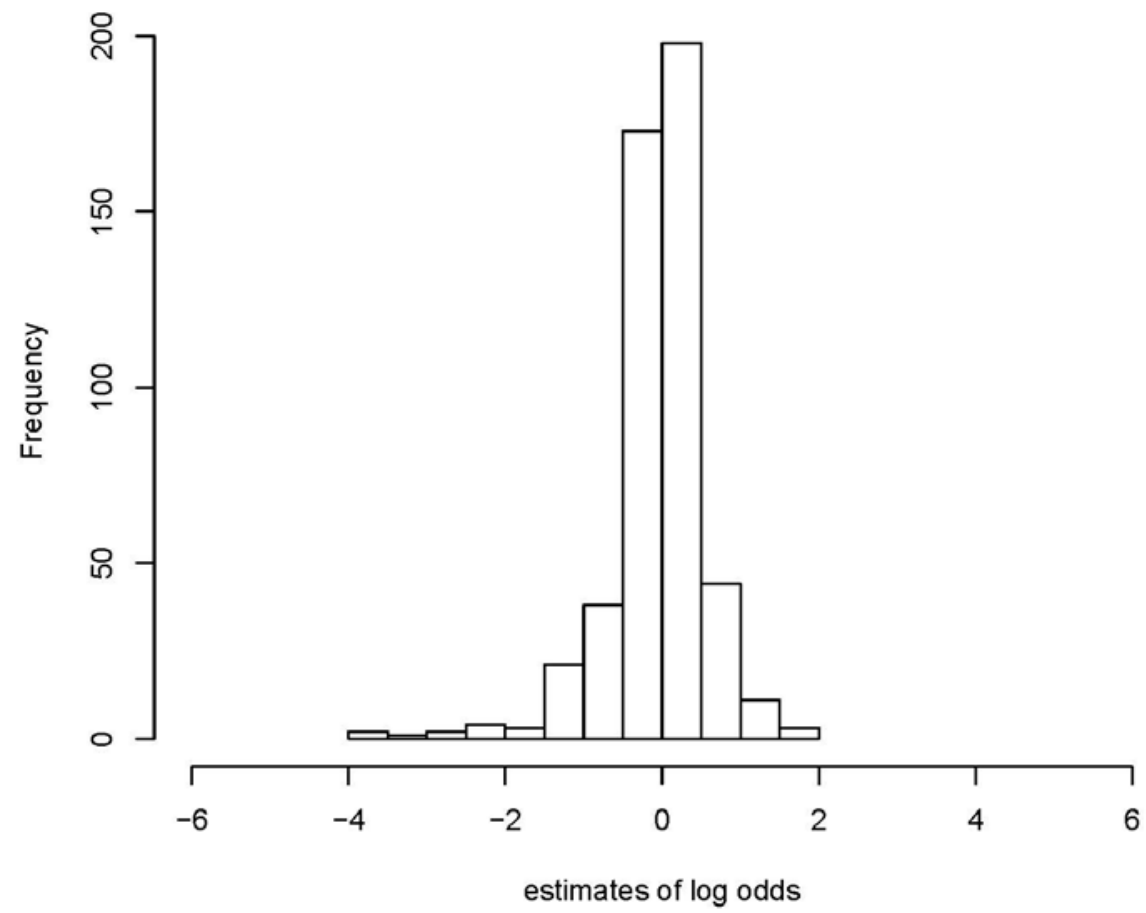

Our statistical models revealed several interesting things. For example, it appears that at least some of the migration at younger ages in our study villages is related to schooling (Figure 1). While there are local primary schools, older students must travel from their natal villages to attend secondary schools. Some secondary schools are boarding schools, meaning that children will reside at the school location until the end of the term. Most migration at younger ages is dependent on adult (parental) migration. In our dataset there were very few cases of children under age 5 who moved out without there also being one or two adults from the same household who moved out - which we interpret as parents leaving with their dependent children. We found no difference in sex with regard to out-migration in children less than age 5 , and we believe that this is an intuitive finding: parents take both sons and daughters with them. 
Larger households and households with higher C/P ratios were more likely to experience childhood out-migration. This finding may be related to the age structure and family dynamics of household members as well as socio-cultural patterns and norms. For example, many households in our study villages consist of multiple nuclear families. As those families grow one family may move out to create its own household. Previous research in Karen villages indicates that having more than two reproductiveage couples in a single household is undesirable (Kunstadter 1984; Rajah 2008). An older daughter whose nuclear family is sharing her parent's household may be required to move out when a younger daughter subsequently marries and moves in. In such cases there are often young children who also move out with the couple. We expect that such households would include more household members and have higher $\mathrm{C} / \mathrm{P}$ ratios (with more children and elderly household members).

Conversely, our model for adults found a strong association between sex and outmigration. Migration in working-age adults within our study population can be broadly split into two groups: those related to marriage and postmarital residence, and those related to occupation and economic opportunities. Both have gender- or sex-specific patterns. For example, the Karen have traditionally been uxorilocal (Rajah 2008); that is, males who marry are likely either to join the household of the female spouse's family of orientation or to establish a new household near her family's house. However, this pattern does not fully explain the out-migration we are seeing in our study villages. It is likely that many of the young females (around 15 years old) who are moving out are also doing so for marriage, despite uxorilocality. This may be consistent with a society that is acculturating to surrounding socio-cultural groups, and with traditions that are either changing or are loosely enforced. Furthermore, while postmarital residence probably does explain some of the out-migration we are seeing, it may be a small fraction of the total. For example, those adults who are moving out with children are also leaving households with high $\mathrm{C} / \mathrm{P}$ ratios. Since they make up a small minority of the overall group of adult out-migrants, the effect of the $\mathrm{C} / \mathrm{P}$ ratio on adult outmigration continues to be negative.

Much of the adult out-migration in our dataset is probably attributable to economic factors and, in some cases, to breaks in the agricultural calendar. Our models suggest that, aside from being mostly male, adult out-migrants are more likely to come from households with more household members and low C/P ratios. We interpret both of these household-level factors to reflect the household economy, more specifically, the household workforce. Households with few 'producers' and many dependents, and therefore a high C/P ratio, are unlikely to have 'extra' workers who are free to move out for any reason. In other words, households with high C/P ratios are already constrained to the point that the loss of a household producer could have severe consequences. For 
example, households with a single parent and several children, or with elderly grandparents taking care of their grandchildren, are unlikely to have adults move out.

These findings are relevant to migration theory that deals with migration, economics, and household-level factors. For example, the New Economics of Labor Migration (NELM) model proposes that migrations are the result of household-level decision-making and, furthermore, that it can be viewed as a means of diversifying risks in households and regions where the year-to-year maintenance of household food stores is unstable (Stark and Bloom 1985). With regard to our findings, households with high $\mathrm{C} / \mathrm{P}$ ratios may be those with the greatest risk but they are also households with the smallest capabilities of diversifying risk. Conversely, households with 'extra' workingage individuals appear to be most capable of sending migrants and potentially increasing household well-being. While we are not able to completely address this in our model, it is at least imaginable that a continuum in household wealth exists and that there is a threshold below which households that need to increase household wealth are unable to do so.

This pattern is also potentially related to the growing literature on poverty traps (Bonds et al. 2010; Bowles et al. 2007; Collier et al. 2003; Dasgupta et al. 2005). Individuals who live in households that have fallen below a threshold level of poverty are essentially 'trapped' in a cycle of poverty owing to a lack of resources, health conditions, civil conflict, and environmental degradation. Poor children who grow up with fewer resources are likely to suffer lifelong consequences of such conditions. As they age and form their own households they are likely to take those conditions with them, establishing a new household with children that are likewise reared in a resourcepoor environment, in a household that is perpetually trapped in poverty, ultimately continuing an inter-generational cycle of poverty.

Furthermore, while we found our model strata that dealt with elderly (70 plus) outmigration to be unreliable because of the dearth of out-migration events in that age group, this lack of mobility may in itself represent an interesting finding. If the elderly in these populations are less mobile they may also be less able to seek healthcare treatment or other important services.

Finally, while our data do not cover a long enough period to examine seasonal patterns, there is some evidence that migration peaks during off times in the agricultural year (Figure 1). In our study population adult males work heavily during the planting and harvesting seasons but may have more free time during the rest of the year. During slack seasons males may engage in hunting, fishing, lumbering, or other forms of subsistence or cash labor. There are potential epidemiologic implications for this migration pattern. Previous research in SE Asia has indicated that working age males are at increased risk of infection by some forms of malaria (especially Plasmodium falciparum) (Lin et al. 2009; Wiwanitkit 2002). There are multiple ways that this could 
be related to migration. For example, migrants that live in regions with no malaria can travel to malarial areas, become infected, and transport the disease back to their places of origin. Conversely, migrants who live in malarial regions may transport the disease to regions without malaria when they travel (Le Menach et al. 2011). Further research will investigate this potential link between malaria and migration.

Also, in at least some agricultural populations, even marriage patterns are shaped by the agricultural year. Marriage seasonality reflects the seasonality of agricultural work, with marriages primarily occurring during relatively slack times of year following the harvesting of crops or the birthing seasons of livestock (Coppa et al. 2001; Gonzalez-Martin 2008; Kussmaul 1985; Wrigley and Schofield 1989). Marriage seasonality affects not only birth seasonality (Abeysinghe 1991; Garcia-Moro et al. 2000; Grech et al. 2003; Greksa 2004; Johnson, Ann, and Palan 1975; Matsuda and Kahyo 1994) but also the temporal patterns of postmarital migration. Future research in this study population will investigate the potential for yearly, seasonal patterns on the timing of out-migration in this region.

There are several limitations to the present study. Perhaps foremost among these is the definition of migrants used in our data: household members who are not expected to return to the household within the next four weeks. There are at least two main problems with this definition. First, migration intentions do not always match migration actions. Second, migrations that occur for shorter periods of time are both important and frequent in our study populations. What our study therefore misses are long-term migrations that were not intended (or expressed to other household members) and shortterm, circular migrations. Our guess is that, if we did include these migration events in our data, it would not greatly change our model results with regard to household- and individual-level predictors of migration. However, given a longer set of observations, and the missing short-term migrations, we might expect to uncover strong seasonality in migration that would largely match the agricultural calendar.

Another major limitation to this study is the absence of information about household wealth, landholding, or savings. These factors are obviously important with regard to household well-being and could influence migration decisions. In our model we included uncensored household characteristics as a single random effect in an attempt to account for these types of unexplained heterogeneity. It is our opinion that the inclusion of such covariates would almost certainly provide deeper insight into, and more information about, the influence of different household-level factors on outmigration. Measurements of household wealth might have provided stronger and more proximate indicators of the determinants of migration decisions.

Our models indicate that, in addition to the age and sex of the individual, household-level factors such as the number of household members and $\mathrm{C} / \mathrm{P}$ ratios can be strong predictors of individual-level out-migration. We also argue that while $\mathrm{C} / \mathrm{P}$ 
ratios are notoriously difficult to calculate because of the weighting system involved, they are an improvement over dependency ratios and, with a little ethnographic insight, can be robustly estimated. Furthermore, our sensitivity-analysis approach to analyzing potential relations between $\mathrm{C} / \mathrm{P}$ ratios and out-migration is novel. Our simulation results indicate a range of potential outcomes, under various weighting schemes, and therefore give us a way to understand the sensitivity of our model results to our model inputs.

Finally, a potentially interesting insight from these data and models concerns the unit of time. It makes sense that household dynamics shift over time, as the age structure of household members also changes. However, our data and models suggest that household dynamics also shift over very short intervals (two weeks) and that those shifting dynamics are also related to demographic forces such as migration.

\section{Acknowledgements}

This study is partially supported by NIAID (NIH U19AI089672). We acknowledge assistance provided by the Population Research Center at Penn State University, which is supported by an infrastructure grant by the National Institutes of Health (2R24HD041025-11). We would also like to acknowledge data collection by staff under Dr. Jeeraphat Sirichaisinthop at the Vector Borne Disease Training Center in Saraburi, staff under Dr. Jetsumon Sattabongkot at Mahidol University, and staff from the Department of Public Health in Tha Song Yang District, Tak Province, Thailand. 


\section{References}

Abeysinghe, T. (1991). A seasonal analysis of Chinese births. Journal of Applied Statistics 18: 275-286. doi:10.1080/02664769100000021.

Barron, S., Okell, J., Yin, S.M., Vanbik, K., Swain, A., Larkin, E., Allott, A.J., and Ewers, K. (2007). Refugees From Burma: Their backgrounds and refugee experiences. Washington, DC: Cultural Orientation Resource Center; Center for Applied Linguistics. http://www.cal.org/resources/pubs/burmese.html.

Behrman, J.R. and Wolfe, B.L. (1984). Micro determinants of female migration in a developing country: labor market, demographic marriage market and economic marriage market incentives. Research in Population Economics 5: 137-166.

Benefice, E., Cames, C., and Simondon, K. (1999). Growth and maturation of Sereer adolescent girls (Senegal) in relation to seasonal migration for labor. American Journal of Human Biology 11: 539-550. doi:10.1002/(SICI)15206300(1999)11:4<539::AID-AJHB14>3.0.CO;2-G.

Bohra-Mishra, P. and Massey, D.S. (2011). Individual decisions to migrate during civil conflict. Demography 48(2): 401-424. doi:10.1007/s13524-011-0016-5.

Bonds, M.H., Keenan, D.C., Rohani, P., and Sachs, J.D. (2010). Poverty trap formed by the ecology of infectious diseases. Proceedings of the Royal Society B: Biological Sciences 277(1685): 1185-1192.

Bowles, S., Durlauf, S.N., and Hoff, K. (2007). Poverty traps. Princeton, NJ: Princeton University Press.

Cain, M.T. (1977). The economic activities of children in a village in Bangladesh. Population and Development Review 3(3): 201-227. doi:10.2307/1971889.

Caldwell, J.C. (1976). A restatement of demographic transition theory. Population and Development Review 2(3/4): 321-366. doi:10.2307/1971615.

Chayanov, A.V. (1966). The peasant family and the influence of its development on economic activity. Madison, WI: University of Wisconsin Press.

Collier, P., Hoeffler, A., Elliot, H., Hegre, H., Reynal-Querol, M., and Sambanis, N. (2003). Breaking the conflict trap: Civil war and development policy. Oxford and Washington, D.C.: Oxford University Press and World Bank.

Coppa, A., Di Donato, L., Vecchi, F., and Danubio, M. (2001). Seasonality of marriages and ecological contexts in rural communities of central-southern Italy (Abruzzo), 1500-1871. Collegium Antropologicum 25: 403-412. 
Cui, L., Yan, G., Sattabongkot, J., Cao, Y., Chen, B., Chen, X., Fan, Q., Fang, Q., Jongwutiwes, S., Parker, D., Sirichaisinthop, J., Kyaw, M.P., Su, X.Z., Yang, H., Yang, Z., Wang, B., Xu, J., Zheng, D., Zhong, D., and Zhou, G. (2012). Malaria in the Greater Mekong Subregion: Heterogeneity and complexity. Acta Tropica 121(3): 227-239. doi:10.1016/j.actatropica.2011.02.016.

Cui, L., Yan, G., Sattabongkot, J., Chen, B., Cao, Y., Fan, Q., Parker, D., Sirichaisinthop, J., Su, X.Z., Yang, H., Yang, Z., Wang, B., and Zhou, G. (2012). Challenges and prospects for malaria elimination in the Greater Mekong Subregion. Acta Tropica 121(3): 240-245. doi:10.1016/j.actatropica.2011. 04.006.

Curran, S. (2002). Migration, social capital, and the environment: Considering migrant selectivity and networks in relation to coastal ecosystems. Population and Development Review 28: 89-125.

Curran, S.R. and Saguy, A.C. (2001). Migration and cultural change: A role for gender and social networks. Journal of International Women's Studies 2(3): 54-77.

Dasgupta, S., Deichmann, U., Meisner, C., and Wheeler, D. (2005). Where is the poverty-environment nexus? Evidence from Cambodia, Lao PDR, and Vietnam. World Development 33: 617-638. doi:10.1016/j.worlddev.2004.10.003.

De Jong, G.F. and Gardner, R.W. (1981). Migration decision making: Multidisciplinary approaches to microlevel studies in developed and developing countries. New York: Pergamon Press.

Entwisle, B., Malanson, G., Rindfuss, R.R., and Walsh, S.J. (2008). An agent-based model of household dynamics and land use change. Journal of Land Use Science 3(1): 73-93. doi:10.1080/17474230802048193.

Ferrari, M.J., Grais, R.F., Bharti, N., Conlan, A.J., Bjornstad, O.N., Wolfson, L.J., Guerin, P.J., Djibo, A., and Grenfell, B.T. (2008). The dynamics of measles in Sub-Saharan Africa. Nature 451(7179): 679-684. doi:10.1038/nature06509.

Fields, G.S. (1976). Labor force migration, unemployment and job turnover. The Review of Economics and Statistics 58(4): 407-515.

Fix, A.G. (1999). Migration and colonization in human microevolution. Cambridge University Press.

Gage, A.J., Sommerfelt, A.E., and Piani A.L. (1996). Household structure, socioeconomic level, and child health in Sub-Saharan Africa. Calverton, MD: Macro International Inc. 
Garcia-Moro, C., Pascual, J., Toja, D., and Walker, P. (2000). Birth seasonality in the early Spanish-Mexican colonists of California (1769-1898). Human Biology 72: 655-674.

Garnier, D., Simondon, K.B., Hoarau, T., and Benefice, E. (2003). Impact of the health and living conditions of migrant and non-migrant Senegalese adolescent girls on their nutritional status and growth. Public Health and Nutrition 6: 535-547. doi:10.1079/PHN2003463.

Gonzalez-Martin, A. (2008). Ecological and cultural pressure on marriage seasonality in the Principality of Andorra. Journal of Biosocial Sicence 40(1): 1-18. doi:10.1017/S0021932007002234.

Grech, V., Savona-Ventura, C., Agius-Muscat, H., and Janulova, L. (2003). Seasonality of births is associated with seasonality of marriages in Malta. Journal of Biosocial Sicence 35(1): 95-105. doi:10.1017/S0021932003000956.

Greksa, L. (2004). Birth seasonality in the Old Order Amish. Journal of Biosocial Science 36(3): 299-315. doi:10.1017/S0021932003006254.

Hadley, C., Belachew, T., Lindstrom, D., and Tessema, F. (2011). The shape of things to come? Household dependency ratio and adolescent nutritional status in rural and urban Ethiopia. American Journal of Physical Anthropology 144(4): 643-652. doi:10.1002/ajpa.21463.

Hammel, E.A. (2005). Chayanov revisited: A model for the economics of complex kin units. Proceeds of the National Academies of Science of the United States of America 102: 7043-7046. doi:10.1073/pnas.0501987102.

Jacobsen, J.P. and Levin, L.M. (1997). Marriage and migration: Comparing gains and losses from migration for couples and singles. Social Science Quarterly 78(3): 688-709.

Jennings, J.A., Wood, J.W., and Johnson, P.L. (2011). Household-level predictors of the presence of servants in northern Orkney, Scotland, 1851-1901. History of the Family 16: 278-291. doi:10.1016/j.hisfam.2011.01.002.

Johnson, J., Ann, T., and Palan, V. (1975). Seasonality of births for West Malaysia's two main racial groups. Human Biology 47(3): 295-307.

Kaplan, H. (1994). Evolutionary and wealth flows theories of fertility: Empirical tests and new models. Population and Development Review 20(4): 753-791. doi:10.2307/2137661. 
Katz, E. (2000). Individual, household and community-level determinants of migration in Ecuador: Are there gender differences? [unpublished manuscript] New York: Department of Economics, Barnard College.

Kramer, K.L. (2005). Maya children: Helpers at the farm. Harvard University Press.

Kramer, K.L. and Boone, J.L. (2002). Why intensive agriculturalists have higher fertility: A household energy budget approach. Current Anthropology 43(3): 511-517. doi:10.1086/340239.

Kunstadter, P. (1972). Demography, ecology, social structure and settlement patterns. In: Boyce, A. and Harrison, G. (eds.). The Structure of Human Populations. Oxford: Clarendon Press.

Kunstadter, P. (1984). Cultural ideals, socioeconomic change, and household composition: Karen, Lua', Hmong and Thai in Northwestern Thailand. In: Netting, R.McC., Wilk, R.R., and Arnould, E.J. (eds.). Households: Comparative and historical studies of the domestic group. Berkeley: University of California Press: 299-329.

Kunstadter, P. (1983). Karen agro-forestry: Processes, functions, and implications for socio-economic, demographic, and environmental change in northern Thailand. Mountain Research and Development 3(4): 326-337. doi:10.2307/3673036.

Kussmaul, A. (1985). Time and space, hoofs and grain: The seasonality of marriage in England. Journal of Interdisciplinary History 15(4): 755-779. doi:10.2307/ 204278.

Le Menach, A., Tatem, A.J., Cohen, J.M., Hay, S.I., Randell, H., Patil, A.P., and Smith, D.L. (2011). Travel risk, malaria importation and malaria transmission in Zanzibar. Scientific Reports 1(93).

Lee, E.S. (1966). A theory of migration. Demography 3(1): 47-57. doi:10.2307/ 2060063.

Lee, J.Z. and Campbell, C.D. (2007). Fate and fortune in rural China: Social organization and population behavior in Liaoning 1774-187. Cambridge University Press.

Lee, R.D. and Kramer, K.L. (2002). Children's economic roles in the Maya family life cycle: Cain, Caldwell, and Chayanov revisited. Population and Development Review 28: 475-499. doi:10.1111/j.1728-4457.2002.00475.x. 
Parker et al.: Household ecology and out-migration among ethnic Karen along the Thai-Myanmar border

Lee, T.J., Mullany, L.C., Richards, A.K., Kuiper, H.K., Maung, C., and Beyrer, C. (2006). Mortality rates in conflict zones in Karen, Karenni, and Mon states in eastern Burma. Tropical Medicine \& International Health 11(7): 1119-1127. doi:10.1111/j.1365-3156.2006.01651.x.

Lieberman, D. (1993). The rise and fall of seasonal mobility among hunter-gatherers. Current Anthropology 34(5): 599-641. doi:10.1086/204209.

Lin, H., Lu, L., Tian, L., Zhou, S., Wu, H., Bi, Y., Ho, S.C., and Liu, Q. (2009). Spatial and temporal distribution of falciparum malaria in China. Malaria Journal 8: 130. doi:10.1186/1475-2875-8-130.

Madhavan, S., Schatz, E., and Clark, B. (2009). Effect of HIV/AIDS-related mortality on household dependency ratios in rural South Africa, 2000-2005. Population Studies 63(1): 37-51. doi:10.1080/00324720802592784.

Massey, D.S. (1990). Social structure, household strategies, and the cumulative causation of migration. Population Index 56(1): 3-26. doi:10.2307/3644186.

Massey, D.S. and Espana, F.G. (1987). The social process of international migration. Science 237(4816): 733-738. doi:10.2307/2546522.

Matsuda, S. and Kahyo, H. (1994). Geographical differences and time trends in the seasonality of birth in Japan. Internation Journal of Epidemiology 23(1): 107118. doi:10.1093/ije/23.1.107.

Muth, R.F. (1971). Migration: Chicken or egg? Southern Economic Journal 37(3): 295306. doi:10.2307/1056181.

Nakano, K. (1980). An ecological view of a subsistence economy based mainly on the production of rice in swiddens and in irrigated fields in a hilly region of Northern Thailand. Southeast Asian Studies 18(1): 40-67.

Netting, R. (1993). Smallholders, householders: Farm families and the ecology of intensive, sustainable agriculture. Stanford University Press.

Netting, R. (1982). Some home truths on household size and wealth. American Behavioral Scientist 25(6): 641-662. doi:10.1177/000276482025006004.

Office of National Statistics, Thailand (2010). Thai population and housing census. http://service.nso.go.th/nso/nso_center/project/search_center/23project-en.htm.

Omori, K. and Greksa, L.P. (2002). Seasonal variation in the dietary adequacy of highland Pwo and Sgaw Karen (Thailand). American Journal of Human Biology 14(4): 519-531. doi:10.1002/ajhb.10076. 
Portes, A. and Sensenbrenner, J. (1993). Embeddedness and immigration: Notes on the social determinants of economic action. The American Journal of Sociology 98(6): 1320-1350. doi:10.1086/230191.

Rajah, A. (2008). Remaining Karen: A study of cultural reproduction and the maintenance of identity. Canberra: The Australia National University.

Reyna, S.P. (1976). The extending strategy: Regulation of the household dependency. Journal of Anthropological Research 32(2): 182-198.

Rogers, A. and Castro, L.J. (1981). Model migration schedules. Laxenburg, Austria: International Institute for Applied Systems Analysis.

Sassen, S. (1988). The mobility of labor and capital: A study in international investment and labor flow. Cambridge: Cambridge University Press. doi:10.1017/CBO978 0511598296.

Sjaastad, L.A. (1962). The costs and returns of human migration. The Journal of Political Economy 70(5): 80-93. doi:10.1086/258726.

Skeldon, R. (1985). Population pressure, mobility, and socio-economic change in mountainous environments: Regions of refuge in comparative perspective. Mountain Research and Development 5(3): 233-250. doi:10.2307/3673356.

Sparks, C.S., Wood, J.W., and Johnson, P.L. (2013). Infant mortality and intrahousehold competition in the northern islands of Orkney, Scotland, 1855-2001. American Journal of Physical Anthropology 151(2): 191-201. doi:10.1002/ ajpa.22264.

Stark, O. (1991). The Migration of Labor. New York: Basil Blackwell.

Stark, O. and Bloom, D.E. (1985). The new economics of labor migration. American Economic Review 75(2): 173-178.

Stecklov, G. (1999). Evaluating the economic returns to childbearing in Cote d 'lvoire. Population Studies 53(1): 1-17. doi:10.1080/00324720308072.

Stoddard, S.T., Morrison, A.C., Vazquez-Prokopec, G.M., Paz Soldan, V., Kochel, T.J., Kitron, U., Elder, J.P., and Scott, T.W. (2009). The role of human movement in the transmission of vector-borne pathogens. PLoS Neglected Tropical Diseases 3(7): e481. doi:10.1371/journal.pntd.0000481. 
Parker et al.: Household ecology and out-migration among ethnic Karen along the Thai-Myanmar border

Tatem, A.J. and Smith, D.L. (2010). International population movements and regional Plasmodium falciparum malaria elimination strategies. Proceedings of the National Academy of Sciences 107(27): 12222-12227. doi:10.1073/pnas. 1002971107.

The Border Consortium (2013). Refugee and IDP camp populations: January 2013. http://theborderconsortium.org/camps/2013-01-jan-map-tbc-unhcr.pdf

Todaro, M.P. (1980). Population and Economic Change in Developing Countries. University of Chicago Press.

United Nations, High Commissioner for Refugees (2007). Quick Fact Sheet: Burmese resettlement from Tham Hin Camp in Thailand. Washington, DC. http://www.lcfsrefugees.blogs.com/cultural_descriptions/UNHCR\%20Quick\%2 0Fact\%20Sheet\%20--\%20\%20Burmese.pdf

Walker, A. (2001). The "Karen Consensus", ethnic politics and resource-use legitimacy in Northern Thailand. Asian Ethnicity 2(2): 145-162. doi:10.1080/146313601 20058839.

Wiwanitkit, V. (2002). High prevalence of malaria in Myanmar migrant workers in a rural district near the Thailand-Myanmar border. Scandinavian Journal of Infectious Diseases 34(3): 236-237. doi:10.1080/00365540110077272.

Wrigley, E. and Schofield, R. (1989). The population history of England 1541-1871. Cambridge University Press.

Wood, J.W. (2014). The Biodemography of Subsistence Farming: Population, Food and Family. Cambridge University Press. 